\title{
Synergistic effect of nutlin-3 combined with aspirin in hepatocellular carcinoma HepG2 cells through activation of Bcl-2/Bax signaling pathway
}

\author{
RUNCHEN MIAO ${ }^{1}$, XINSEN XU $^{1}$, ZHIXIN WANG ${ }^{2}$, SUSHUN LIU $^{1}, \mathrm{KAI} \mathrm{QU}^{1}$, WEI CHEN $^{1}$ and $\mathrm{CHANG} \mathrm{LIU}^{1}$ \\ ${ }^{1}$ Department of Hepatobiliary Surgery, The First Affiliated Hospital of \\ Xi'an Jiaotong University, Xi'an, Shaanxi 710061; ${ }^{2}$ Department of Hepatopancreatobiliary Surgery, \\ Affiliated Hospital of Qinghai University, Xining, Qinghai 810000, P.R. China
}

Received July 13, 2017; Accepted December 4, 2017

DOI: $10.3892 / \mathrm{mmr} .2017 .8346$

\begin{abstract}
Aspirin as an antitumor drug has been studied in various malignancies with regards to its effects on apoptosis, proliferation, metastasis and senescence of tumor cells. However, the clinical application is limited by its side effects. Nutlin-3 is a novel antitumor compound, which has not been clinically approved. The present study investigated the value of combining aspirin and nutlin-3 on hepatocellular carcinoma (HCC) cells. MTT was performed to detect the proliferation of HepG2 cells treated with aspirin or/and nutlin-3. Transwell invasion assays were performed to estimate the invasion ability of HepG2 cells treated with aspirin or/and nutlin-3. Then the apoptotic analysis of HepG2 cells evaluated the synergistic effect of aspirin and nutlin-3. Apoptosis markers, including B-cell lymphoma 2 (Bcl-2), Bcl-2-associated X protein (Bax), caspase-3, caspase- 8 and caspase- 9 were estimated by western blot analysis at various time points. In addition, a Xenograft mouse model was established by infection with HepG2 cells, and aspirin and/or nutlin-3 was administrated to verify the anti-apoptotic effect of the two drugs in vivo. A high dose of aspirin and nutlin-3 inhibit the proliferation and apoptosis of HepG2 cells. The antitumor effect was enhanced with the combined treatment of the two drugs, particularly in the group with a low concentration of aspirin and nutlin-3. Nutlin-3 was able to increase the level of Bax in HepG2 cells treated with aspirin significantly after treatment for $8 \mathrm{~h}$. When treated with a low concentration of aspirin and nutlin-3, the level of Bax in HepG2 cells was enhanced for $2 \mathrm{~h}$. In the animal model, tumor volume and tumor angiogenesis were significantly decreased in combination group compared with other groups $(\mathrm{P}<0.01)$.
\end{abstract}

Correspondence to: Dr Chang Liu, Department of Hepatobiliary Surgery, The First Affiliated Hospital of Xi'an Jiaotong University, 277 West Yanta Road, Xi'an, Shaanxi 710061, P.R. China

E-mail: liuchangdoctor@163.com

Key words: hepatocellular carcinoma, aspirin, nutlin-3, apoptosis, Bcl-2/Bax
Although there were side effects in the group treated with aspirin alone, no side effects were observed in the combination group. Nutlin-3 enhanced the apoptotic effect of a low dose of aspirin by upregulating Bax expression in the HepG2 cell line and in vivo. The synergistic effect of nutlin-3 in aspirin antitumor therapy contributed to diminishing the dose of aspirin required and decreased the occurrence of adverse drug events in $\mathrm{HCC}$ through targeting the Bcl-2/Bax signaling pathway.

\section{Introduction}

In the world, hepatocellular carcinoma (HCC) is a common type of tumor and the third most frequent to cause death (1). Women aged 50 or older is the high-risk population of HCC (2). As so far, the most radical therapy of HCC is hepatectomy which can improve the function of liver and patients' quality of life immediately. And the other treatments such as orthotopic liver transplantation (OLT), radiofrequency ablation (RFA) are effective methods. However, the one of features of HCC is have no obvious early symptoms which mean some patients missed the best time of hepatectomy when they were diagnosed as HCC at first. So it is important to search new therapies for getting more effective curative effect. In recent years, the chemotherapy becomes the viable option for the HCC treatment or post-hepatectomy. Sorafenib and the multikinase inhibitor have shown effective activity against HCC and has been approved in part of the world (2). However, the drug resistance hampers the long-term effectiveness of these chemotherapeutic drugs.

Formerly, aspirin is a nonsteroidal anti-inflammatory drug which uses in treatment of tumor complication frequently. In recent years, aspirin was found against cancer. The drug has been demonstrated that it can suppress cancer growth and induce apoptosis and differentiation in some cancers (3-7). Now, the concentration of aspirin is a tissue in clinical application. Aspirin is associated with potential side effects including gastrointestinal and cardiovascular effects. There is a contradiction between the demanded dose and the concentration of occurring adverse effects. It is interest to investigate the union use effect from two drugs together. 
Previous studies showed that the different dose of Aspirin can impact the postoperative survival in subsets of post-esophagectomy patients (8). Patients who had received a low-dose of aspirin daily for more than 5 years showed significant anti-cancer effect compared with treatment without aspirin $(9,10)$. The clear mechanisms of antitumor of Aspirin are inhibition of the cyclooxygenase (COX)-independent mechanisms and inhibition of platelet. A high dose of aspirin can inhibit COX-2 expression which be found abnormal high expression in various cancers (11-14). It also inhibit the phosphatidylinositol 3-kinase-related pathways (PIK3CA) pathway via reduce COX-2 expression to enhance the tumor cells senescence in colorectal cancer and breast cancer (15). The other downstream transcriptional targets interact with the targeted molecules of aspirin including ERK, MAPK and $\mathrm{NF}-\kappa \mathrm{B}$ and so on. Aspirin may induce $\mathrm{COX}-2$ expression through activate inactivation of platelets in epithelial cells of colorectal adenomas and cancers (16). In addition, it is gradually accepted that aspirin can acetylate lysine residues in serum proteins. A report in human breast cancer cells showed Aspirin induced p21 $1^{\mathrm{CIP} 1}$ protein levels in a transient fashion via acetylating the p53 protein markedly.

Nutlin-3 is an MDM2 antagonist which can protect P53 from binding with MDM2 and activate P53 (17). There are a number of studies involving the mechanism of nutlin-3 function for a various of cancers in which nutlin-3 can induce growth inhibition, cell migration and/or apoptosis (18-23). Nutlin-3 can bind with the three hydrophobic amino acid (-Leu26, Trp23, Phe19) of P53 specifically and efficiently. Then it breaks the combination of P53 and MDM2 and gather p53 again to exert antitumor effect including the arrest of tumor cell cycle and the cell apoptosis. Nutlin-3 has been used as a probe compound in preclinical (24). However, because of the dose-dependent toxicities and drug-resistance, Nutlin-3 not be used to cure disease clinically. There is still a long way to use Nutlin-3 in clinical extensively.

Although the intrinsic mechanisms of aspirin on COX and platelet have been well-studied, the certified pathways of Aspirin in P53 network is little. Herein, we hypothesized that the antitumor effects of aspirin may be enhanced by nutlin-3 in HCC cells. Its mechanism involve the P53-dependent pathway. So the aim of the present study was to evaluate the antitumor effect of combined treatment of aspirin and nutlin-3 in human HCC cell lines.

However, whether aspirin combined with nutlin-3 has a synergistic effect on HCC cell lines' proliferation and apoptosis is still unknown. Based on these findings, in the present study, we aim to evaluate the synergistic antitumor effect of aspirin and nutlin-3 combination in human HCC cell lines.

\section{Materials and methods}

Cell culture. Human HCC line (HepG2) was obtained from Shanghai Institute of Biochemistry and Cell Biology, Chinese Academy of Sciences (Shanghai, China). HepG2 cells were cultured in DMEM culture medium (HyClone; GE Healthcare Life Sciences, Logan, UT, USA) supplemented with $10 \%$ FBS (Gibco; Thermo Fisher Scientific, Inc., Waltham, MA, USA), $100 \mathrm{U} / \mathrm{ml}$ penicillin and $100 \mathrm{U} / \mathrm{ml}$ streptomycin. The phenomena of culturing HepG2 cells is a humidified atmosphere containing $5 \%$ carbon dioxide at $37^{\circ} \mathrm{C}$.

Drugs and reagents. Aspirin and Nutlin-3 were purchased by Sigma-Aldrich (Merck KGaA, Darmstadt, Germany). Nutlin-3 was dissolved in dimethyl sulfoxide $(20 \mathrm{mg} / \mathrm{ml})$ and diluted with $\mathrm{H}_{2} \mathrm{O}$. Aspirin was dissolved in dimethyl sulfoxide (20 mg/ml) and diluted with PBS medium. The final concentration of Aspirin and Nutlin-3 is $1 \mathrm{mmol} / \mathrm{l}$ and $5 \mu \mathrm{mol} / \mathrm{l}$, respectively.

MTT assay for cell viability. HepG2 cells were seeded into 96 -well plates at a density of $5 \times 10^{4}$ cells per well, and incubated for $24 \mathrm{~h}$ to make sure all cells attached to the plate sufficiently. Then we would starve the cells by change culture medium without FBS for $12 \mathrm{~h}$. The cells were incubated with aspirin and/or nutlin-3 at varying doses of single drug or its combination for 24,48 or $72 \mathrm{~h}$. After treatments, supernatants were discarded and washed with PBS. The cells were incubated with MTT $(5 \mathrm{mg} / \mathrm{ml}$ in PBS) at $37^{\circ} \mathrm{C}$ for another $4 \mathrm{~h}$. Discard the medium, MTT formazan crystals were dissolved in $200 \mu \mathrm{l}$ DMSO. In the end, it was measured using a POLAR star OPTIMA microplate reader (BMG Labtechnologies, Ortenberg, Germany) at absorbance at $570 \mathrm{~nm}$. Cell viability is equal with the percentage of viable cells in total cell population. Each experiment was performed three replicates.

Colony formation assay. One thousand cells were plated into 6-well plates and incubated in DMEM with 10\% FBS at $37^{\circ} \mathrm{C}$. Seven days later, the cells were fixed and stained with $0.1 \%$ crystal violet. The number of colonies, defined as $>50$ cells/colony, were counted.

Cell migration assays. The invasive potential of cells was measured in 6.5 micrometers Transwell with 8.0 micrometers Pore Polycarbonate Membrane Insert (Corning Incorporated, Corning, NY, USA) according to the manufacturer's instructions. Then HepG2 cells were seeded into the upper chamber with DMEM. The lower chambers were filled with $600 \mu \mathrm{l}$ of DMEM medium with $10 \%$ FBS as chemoattractant. After $48 \mathrm{~h}$, the invasive cells across membrane and adhere to the lower surface of the membrane which were fixed with $4 \%$ paraformaldehyde for $30 \mathrm{~min}$, permeabilized with $0.2 \%$ Triton $\mathrm{X}-100$ at room temperature for $15 \mathrm{~min}$, and then stained with $0.1 \%$ crystal violet for $5 \mathrm{~min}$. Light microscope was used to measure the number of invading cells in five random fields at a magnification of $\mathrm{x} 100$.

Apoptosis assay. Annexin V: PE Apoptosis Detection kit (BD Biosciences, Franklin Lakes, NJ, USA) was used to measure the cells' apoptosis induced by nutlin-3 or/and Aspirin. After treatment for $48 \mathrm{~h}$, cells were digested by pancreatin with EDTA and washed with PBS at $4^{\circ} \mathrm{C}$. Then it were resuspended in $500 \mu \mathrm{l}$ binding buffer $\left(1 \times 10^{6}\right.$ cells per ml) containing $5 \mu \mathrm{l}$ of Annexin V-APC and $5 \mu \mathrm{l}$ of 7-AAD. The cells were incubated for $15 \mathrm{~min}$ at room temperature without light and analyzed by flow cytometry (FACS Calibur; BD Biosciences). Apoptotic cells were analyzed by quadrant statistics of the propidium iodide-negative and 
A
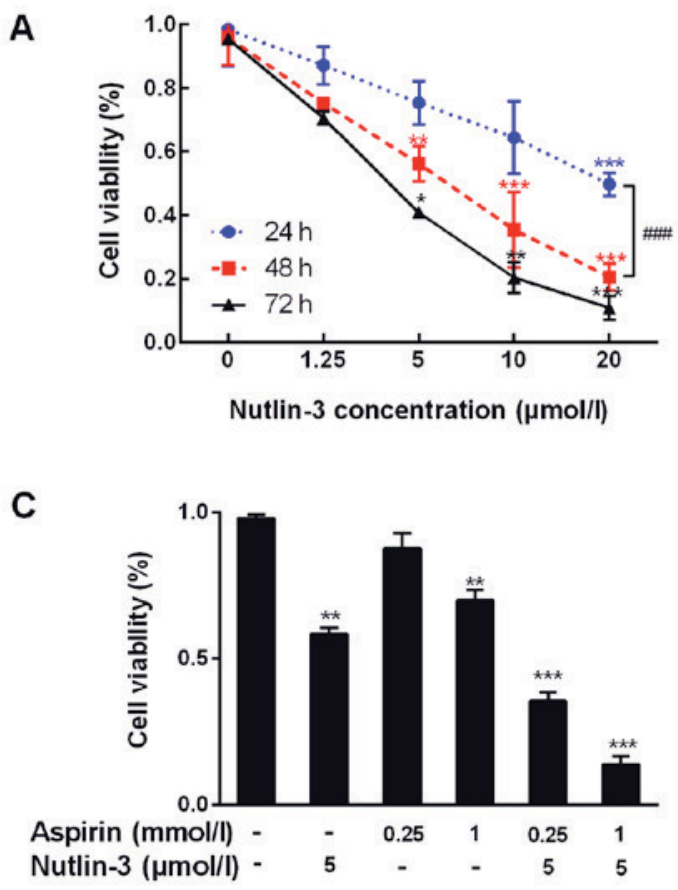

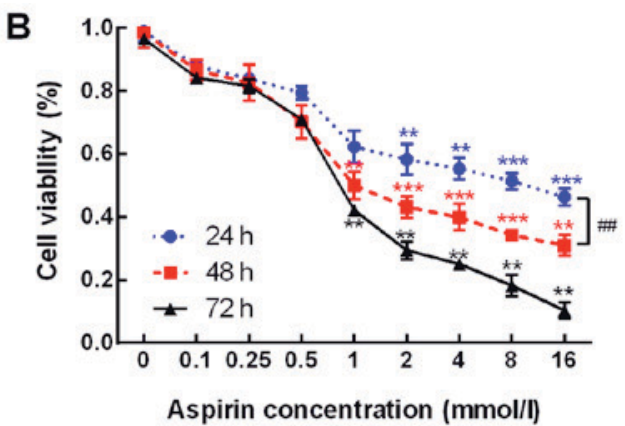

D
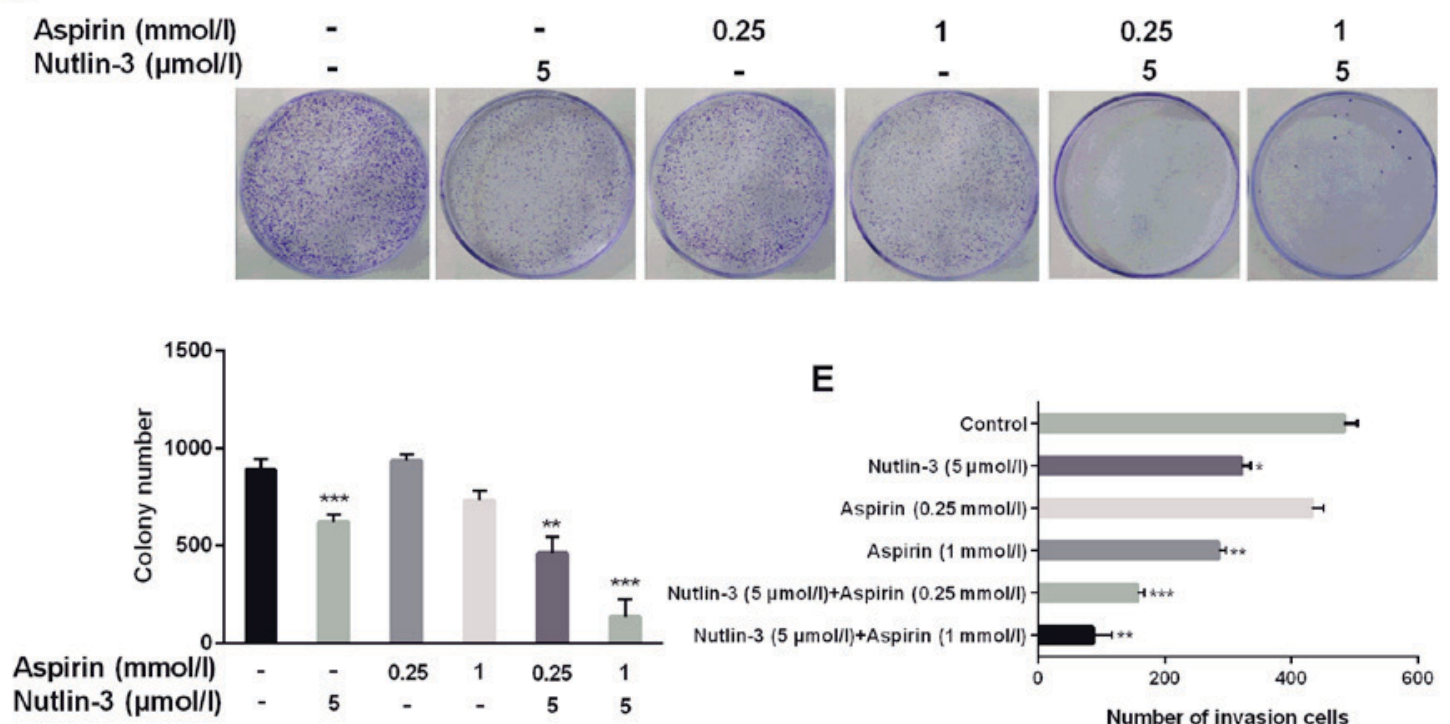

E

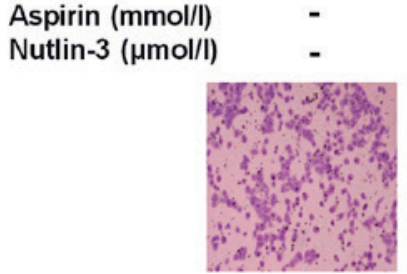

$-$

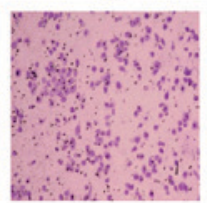

0.25

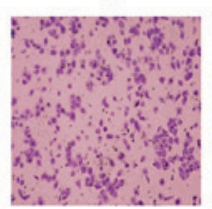

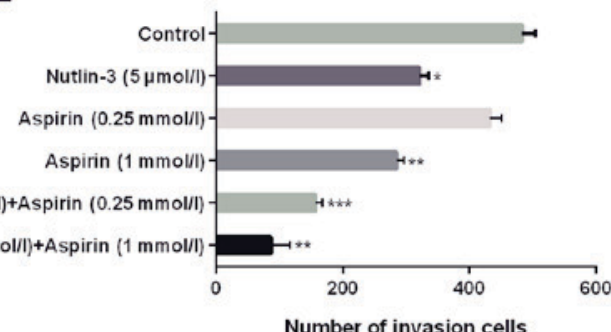

Figure 1. (A) Inhibitory effect of nutlin-3 for the cell proliferation after cultivate cells at different concentration for three times (24, 48 and $72 \mathrm{~h})$, respectively. (B) Inhibitory effect of aspirin for the cell proliferation after cultivate cells at different concentration for three times (24, 48 and $72 \mathrm{~h}$ ), respectively. (C) Cell viability is determined by using MTT assay in HepG2 cells demonstrated by nutlin-3 and aspirin alone or in combination for $48 \mathrm{~h}$. (D) The colony number of HepG2 treated with nutlin-3 and aspirin alone or in combination for $48 \mathrm{~h}$. (E) The ability of migration of HepG2 cells treated with nutlin-3 and aspirin alone or in combination for $48 \mathrm{~h}$. Data are shown by means \pm standard deviation, and data are the average results of three independent experiments. ${ }^{*} \mathrm{P}<0.05,{ }^{* *} \mathrm{P}<0.01$, ${ }^{* * * *} \mathrm{P}<0.001$ vs. 24 h group; ${ }^{\# \#} \mathrm{P}<0.01,{ }^{\# \# \#} \mathrm{P}<0.001$ vs. control groups (nutlin-3 concentration or aspirin concentration=0).

Annexin V-positive cells. The apoptotic index was calculated by the percentage of the propidium iodide-negative and Annexin V-positive cells in total cells.
Protein extraction and western blotting. HepG2 cells were cultured by treating with nutlin-3 and/or aspirin for $48 \mathrm{~h}$ in 6-well plates. Then it was digested by pancreatin with EDTA 


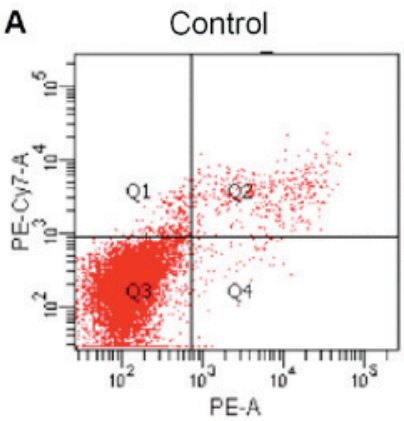

D

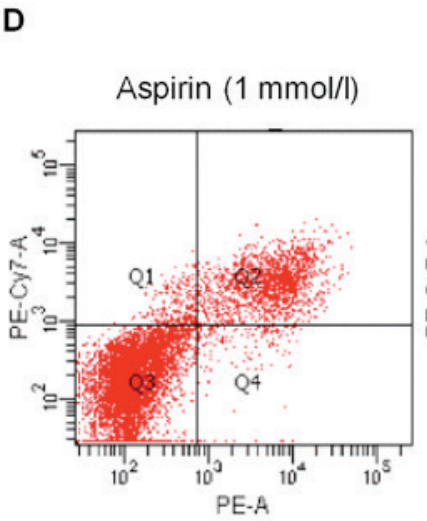

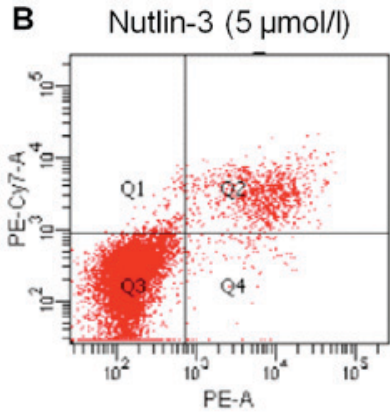

E

Nutlin-3 $(5 \mu \mathrm{mol} / \mathrm{l})$ Aspirin $(0.25 \mathrm{mmol} / \mathrm{l})$

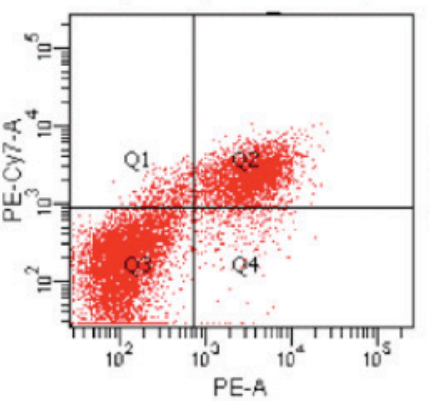

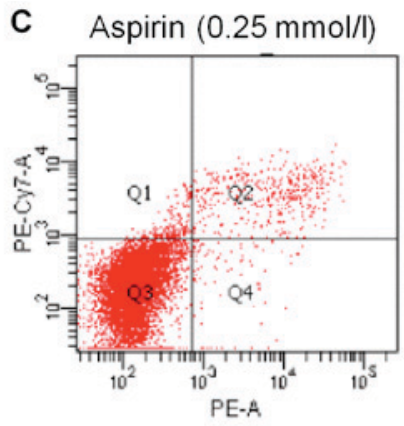

F

G

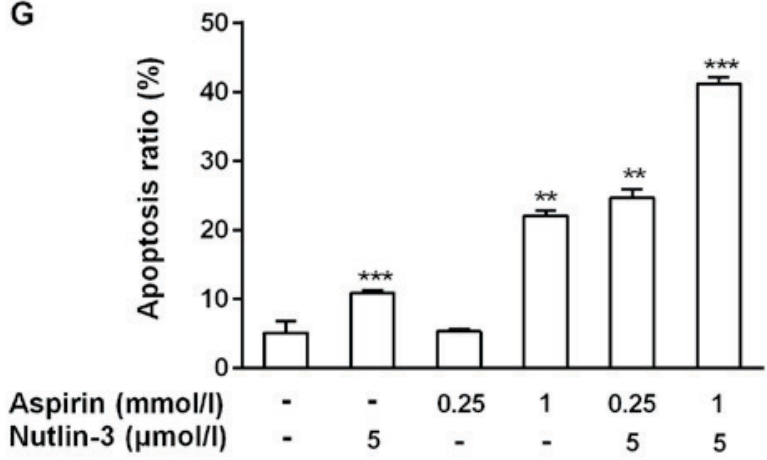

Figure 2. (A-F) The flow cytometry showed the apoptosis of HepG2 cells after treatment; (G) The quantitative figure for apoptosis of HepG2 cells after treatment. Data are means \pm standard deviation (error bars). ${ }^{* *} \mathrm{P}<0.01 ;{ }^{* * *} \mathrm{P}<0.0001$ vs. control.

to collect total cells. The cells were sonicated and centrifuged to collect cell extracts at $12,000 \mathrm{x}$ g for $10 \mathrm{~min}$ at $4^{\circ} \mathrm{C}$. Protein concentrations were determined with a BCA assay. Equal amounts of total proteins were transferred to polyvinylidene difluoride membranes (EMD Millipore, Billerica, MA, USA). After blocking in 5\% non-fat dry milk, the membrane was subsequently immunoblotted with primary antibodies following: Anti- $\beta$-actin, anti-B-cell lymphoma 2 (Bcl-2), anti-Bax, anti-caspase-3, anti-caspase- 8 and anti-caspase- 9 overnight at $4^{\circ} \mathrm{C}$. Next day, immunoreactivity was incubated with HRP conjugated anti-goat or anti-rabbit antibody (Santa Cruz Biotechnology, Inc., Dallas, TX, USA). The signals were visualized by the ECL kit (Pierce; Thermo Fisher Scientific, Inc.). The primary antibodies were all purchased from Santa Cruz Biotechnology, Inc..

Xenograft mouse model. BALB/c nude mice (5 weeks old, 20-25 g) were purchased from Animal Feeding Center of Xi'an Jiaotong University Health Science Center. Animal experimental protocols was approved by the Institutional Animal Care and Use Committee, and the mice were fed in compliance with criteria outlined in the Guide for the Care and Use of Laboratory Animals established by the US National Institutes of Health, strictly. HepG2 cells were harvested and re-suspended sterile, serum-free PBS. The mice were randomized into four groups ( $\mathrm{N}=4$ per group). Then $5 \times 10^{6}$ HepG2 cells were inoculated into each mice on posterior hind flank region subcutaneously. After the injection of HepG2 cells on 3 days, the treatment of Aspirin (13 mg/kg/day, p.o.) and/or Nutlin-3 (200 mg/kg, twice a day, p.o.) was started after the injection of HepG2 cells (25). As a controls group, the mice were administrated by PBS $(0.2 \mathrm{ml} / \mathrm{kg} /$ day $) .3$ weeks after daily administration, mice were killed. The tumor was then removed and underwent the immunohistochemistry. Tumor growth was monitored twice weekly. The length (L) and the width (W) of the tumors were measured and the volume (V) of each tumor was calculated with the formula: $\mathrm{V}=\mathrm{Lx} \mathrm{W} \mathrm{W}^{2} / 2$ (26). The study was approved by the Animal Research Committee of Xi'an Jiaotong University Health Science Center.

Statistical analysis. Experiments were performed with values expressed as mean \pm standard deviation. All statistical analyses 
were conducted using the Graphpad Prism 6.0 software. The correlation differences between the respective groups were evaluated by either ANOVA or nonparametric test. $\mathrm{P}<0.05$ was considered to indicate a statistically significant difference.

\section{Results}

Aspirin and nutlin-3 inhibits the proliferation and migration of HepG2 cells. As we all know, nutlin-3 inhibits the proliferation in HCC cells which were confirmed by previous studies $(27,28)$. To study the function of aspirin in anti-proliferative and the effect of cooperating with nutlin-3, aspirin and nutlin-3 were detected by concentration gradient in HepG2 cell line separately. Then the MTT assay were performed for 24, 48, $72 \mathrm{~h}$. We can easily found that both aspirin (Fig. 1A) and nutlin-3 (Fig. 1B) would inhibit the growth of viable HCC cells in a dose-dependent manner significantly. After $48 \mathrm{~h}$ treatment for aspirin or nutlin-3, the anti-proliferation effect of the two drugs showed statistical significance. Based on the IC50 dose, the experimental concentration of nutlin-3 in HepG2 cells was determined as $5 \mu \mathrm{mol} / 1$ at $48 \mathrm{~h}$. The experimental concentration of aspirin was determined as $1 \mu \mathrm{mol} / 1$ at $48 \mathrm{~h}$. Moreover, the low dose of aspirin identified as $0.25 \mathrm{mmol} / \mathrm{l}$ were used to investigate the side effect.

Next, aspirin (1 or $0.25 \mathrm{mmol} / \mathrm{l})$ and nutlin-3 $(5 \mu \mathrm{mol} / \mathrm{l})$ were used in HepG2 cells simultaneously for $48 \mathrm{~h}$, the MTT assay showed a remarkable decrease in HepG2 viable cell numbers and the effect of growth inhibitory is remarkly stronger compared with control or drug treatment alone (Fig. 1C). Colony formation assays revealed that aspirin $(1 \mathrm{mmol} / \mathrm{l})$ and nutlin-3 $(5 \mu \mathrm{mol} / \mathrm{l})$ formed significantly less colonies than control in HepG2 cells. While the low dose of aspirin $(0.25 \mathrm{mmol} / \mathrm{l})$ formed a similar colonies as control. When combined aspirin and nutlin-3, the colonies of HepG2 cells is higher than drug administration alone and control (Fig. 1D). Furthermore, the high aggressive potency is one of the key feature of malignant cells. The migration assays were performed to evaluate the migration capabilities of HepG2 cells treated with aspirin and nutlin-3. Co-treatment of aspirin ( $1 \mathrm{mmol} / \mathrm{l})$ and nutlin-3 (5 $\mu \mathrm{mol} / \mathrm{l})$ suppressed cells' migration (Fig. 1E) compared with control or drug treatment alone.

Aspirin enhances nutlin-3-induced apoptosis of HCC cell. Aspirin can induce tumor cells apoptosis by signal pathways. We speculated that aspirin and nutlin-3 can regulate the tumor cells proliferation via affects apoptosis in HepG2 cells. To study the potential synergistic effect of apoptosis for aspirin and nutlin-3, HepG2 cells were treated for $48 \mathrm{~h}$ in six groups. Then Annexin V-APC/7-AAD Apoptosis Detection kit were used to stain the apoptotic cells in six groups respectively. Compared with control group, the two drugs are all increase the apoptosis ratio of HepG2 cells, low dose of aspirin showed no statistical difference. But compared with either aspirin or nutlin-3 alone, the combination of aspirin ( 1 or $0.25 \mathrm{mmol} / \mathrm{l})$ and nutlin-3 $(5 \mu \mathrm{mol} / \mathrm{l})$ both induced a significant increase in HepG2 cells (Fig. 2). These results suggested that nutlin-3 can enhance the apoptotic effect of aspirin and nutlin-3 can enhance the apoptot ic effect of a low dose of aspirin in HCC HepG2 cells.

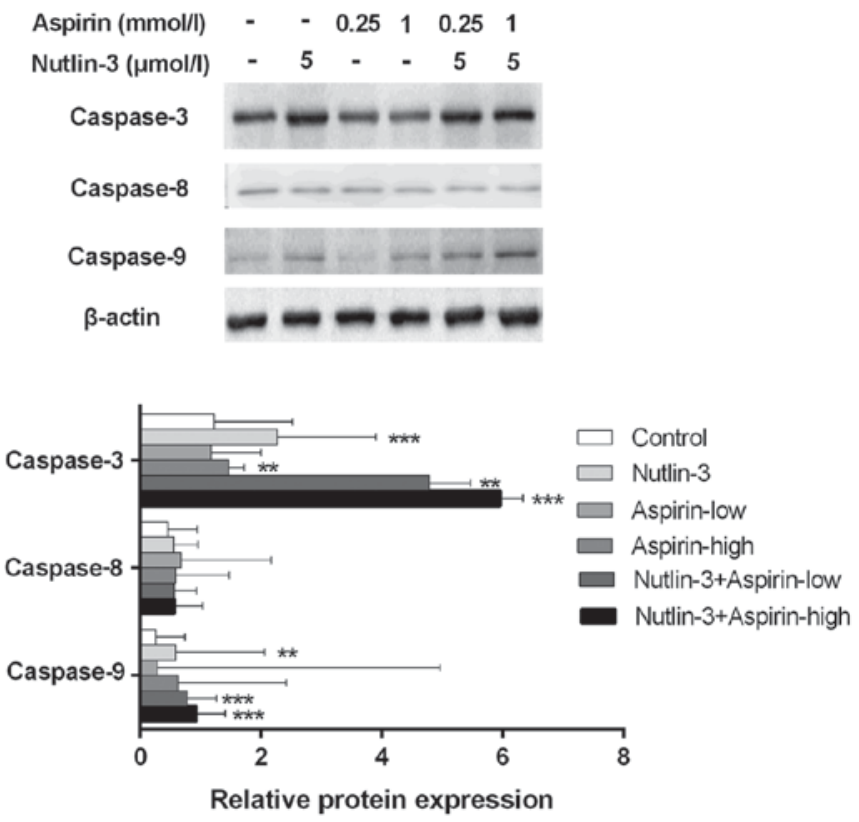

Figure 3. The apoptotic effect of Nutlin-3 and a different dose of Aspirin via regulating caspase cascade proteins. Data are means \pm standard deviation (error bars). ${ }^{* *} \mathrm{P}<0.01 ;{ }^{* * *} \mathrm{P}<0.0001$ vs. control.

Combination of aspirin and nutlin-3 enhances apoptosis via caspase cascade proteins. In previous combination treatment of nutlin-3 and aspirin, significant decline of cell numbers was observed. To confirm the mechanism induced apoptosis by the co-treatment, we extract the total protein from HepG2 cells treated with the two drugs alone or in combination respectively to detect the change of apoptotic protein biomarkers. The results showed that the administration of nutlin-3 can increase the levels of caspase-3 and caspase-9. While there is no change on caspase-8 in HepG2 cells treated with nutlin-3. A low dose of aspirin $(0.25 \mathrm{mmol} / \mathrm{l})$ did not change the level of caspase- 9 and caspase-3. However, the result of the combined treatment is the expression of caspase- 9 and caspase- 3 go up which was significantly obvious. The expression of caspase- 8 showed no change when treated with nutlin-3 and Aspirin alone or in combination (Fig. 3).

Nutlin-3 activates the Bax/Bcl-2 signaling pathway in HepG2 cells treated with A low dose of aspirin. As we all know, $\mathrm{Bcl}-2 / \mathrm{Bax}$ is a specific signaling pathways downstream of $\mathrm{P} 53$, and it is a downstream of caspase-3. We wonder to know if $\mathrm{Bcl}-2 / \mathrm{Bax}$ pathway were involved in the synergistic effect of nutlin-3 combined with Aspirin. The western blot results found that nutlin-3 can increase the level of Bax and decrease the level of Bcl-2 in HepG2 cells. The expression of Bax was no change by aspirin $(0.25 \mathrm{mmol} / \mathrm{l})$ and enhanced by the high dose of aspirin. In addition, the expression of Bcl-2 have no change for aspirin. Furthermore, when treated with aspirin $(0.25 \mathrm{mmol} / \mathrm{l})$ and nutlin-3 $(5 \mu \mathrm{mol} / \mathrm{l})$, tumor cells showed high expression of Bax levels than when treated with nutlin-3 or aspirin alone (Fig. 4A). So we suggested that nutlin-3 enhanced the apoptotic effect of aspirin through Bcl-2/Bax signal pathway.

Next, we choose a low dose of aspirin $(0.25 \mathrm{mmol} / \mathrm{l})$ to verify the mechanism. Nutlin-3 $(5 \mu \mathrm{mol} / \mathrm{l})$ and aspirin 


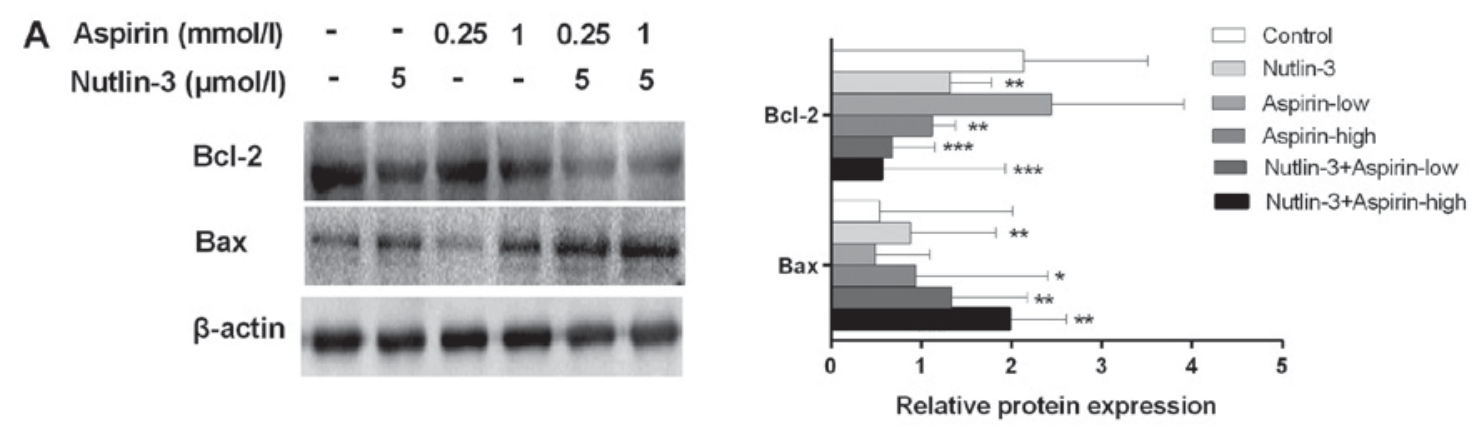

B

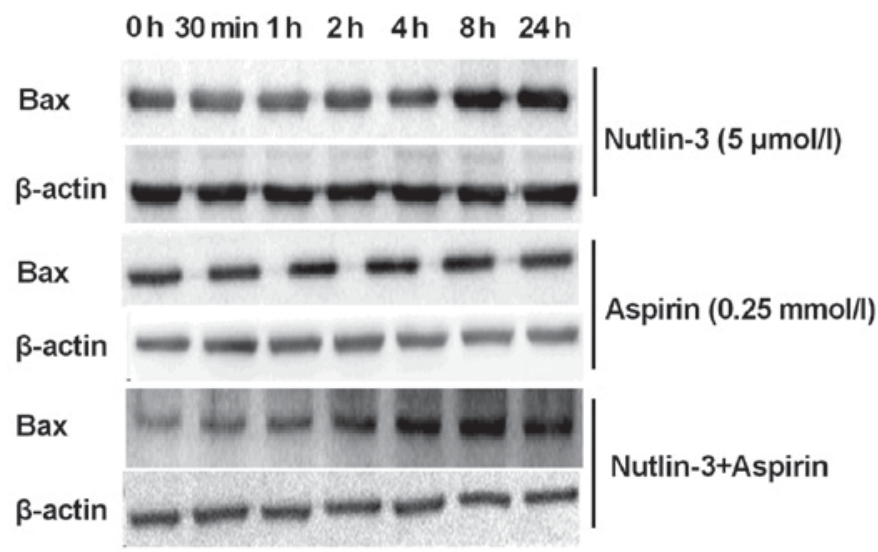

Figure 4. (A) the expression of Bax were detect in six groups (HepG2 cells, HepG2 cells treated with nutlin-3 (5 $\mu$ mol/1), HepG2 cells treated with aspirin ( 0.25 or $1 \mathrm{mmol} / \mathrm{l})$, and HepG2 cells co-treated with nutlin-3 $(5 \mu \mathrm{mol} / \mathrm{l})$ and Aspirin $(0.25$ or $1 \mathrm{mmol} / \mathrm{l})$. (B) Expression of Bax in HepG2 cells stimulated by nutlin-3 $(5 \mu \mathrm{mol} / 1)$ at different time points. Data are means \pm standard deviation (error bars). ${ }^{*} \mathrm{P}<0.05 ;{ }^{* *} \mathrm{P}<0.01 ;{ }^{* * *} \mathrm{P}<0.0001$ vs. control.

$(0.25 \mathrm{mmol} / \mathrm{l})$ were used for detecting the change of Bax at various time points in HepG2 cells. After treated with nutlin-3 for $8 \mathrm{~h}$ in HepG2 cells, the total Bax expression was increased significantly in a time-dependent manner (Fig. 4B), but the group treated with aspirin at a low concentration have no change. Furthermore, when nutlin-3 (5 $\mu \mathrm{mol} / 1)$ and aspirin $(0.25 \mathrm{mmol} / \mathrm{l})$ were used together, the expression of Bax was significantly increased beginning after treated with two drugs for $2 \mathrm{~h}$.

Combination of nutlin-3 and aspirin reduces proliferation and tumor angiogenesis of HCC cells in vivo. In order to verify whether the combination of aspirin and nutlin-3 could inhibit tumor growth, the in vivo activity of combination on HCC cells were also evaluated. Subcutaneous inoculation of HepG2 cells into nude mice resulted in a tumor formation at the site of injection in all mice. There are four group in which mice administrated with PBS $(0.2 \mathrm{ml} / \mathrm{kg} / \mathrm{day})$, a low dose of aspirin (13 mg/kg/day, p.o.), nutlin-3 (200 mg/kg, twice a day, p.o.) and a low dose of aspirin $(13 \mathrm{mg} / \mathrm{kg} / \mathrm{day}$, p.o.) combined with nutlin-3 (200 mg/kg, twice a day, p.o.), respectively. One mice in the group treated with aspirin alone died during the experiment because of gastric mucosa injury. But all the mice from other groups survived until the experiment stopped. The tumor growth ability of HepG2 cells in the combination group is weakest among four groups. And no significant difference was observed in tumor volume of control group and aspirin management group (Fig. 5A). The Bax immuno-histochemical reactions were performed in the tumor tissue (Fig. 5B). Bax was markedly expressed in group treated with aspirin and nutlin-3. Next, the angiogenesis-associated proteins VEGF, and CD31 were detected in the four group. VEGF, and CD31 protein expressions were decreased in the group in which mice treated with nutlin-3. The expression of VEGF, and CD31 is lowest in the four groups (Fig. 5C). Therefore, nutlin-3 cooperated with aspirin might suppress the proliferation ability of tumor cells and inhibit tumor angiogenesis via up-regulating the expression of Bax in vivo. Moreover, nutlin-3 can attenuate the toxicity in aspirin treatment.

\section{Discussion}

In 1979, the HepG2 cell line was firstly established by Barbara Knowles and colleagues, and reported as a HCC (29). Over the next few decades, HepG2 has been widely used to investigate metabolism, development, oncogenesis (chemocarcinogenesis and mutagenesis), and hepatotoxicity in HCC. However, in 2009, López-Terrada et al reported HepG2 originated as a hepatoblastoma (HB) and not a HCC according to array comparative genomic hybridization $(\mathrm{CGH})$ analysis and a series of experiments (30). HB is a primary hepatic malignant tumor and originated from primitive hepatic stem cells. It commonly occurred in children. Now, HepG2 cell lines were used to explore molecular mechanism in HB. Even so, more than 2012 researches used HepG2 to investigate HCC from 2009 to 2017 according to PubMed. In the study, the synergistic anti-cancer effects of aspirin and nutlin-3 have been conformed in HepG2. There were even some hints the synergistic anticancer effects of aspirin and nutlin-3 are exist not only in liver cancer but 
A
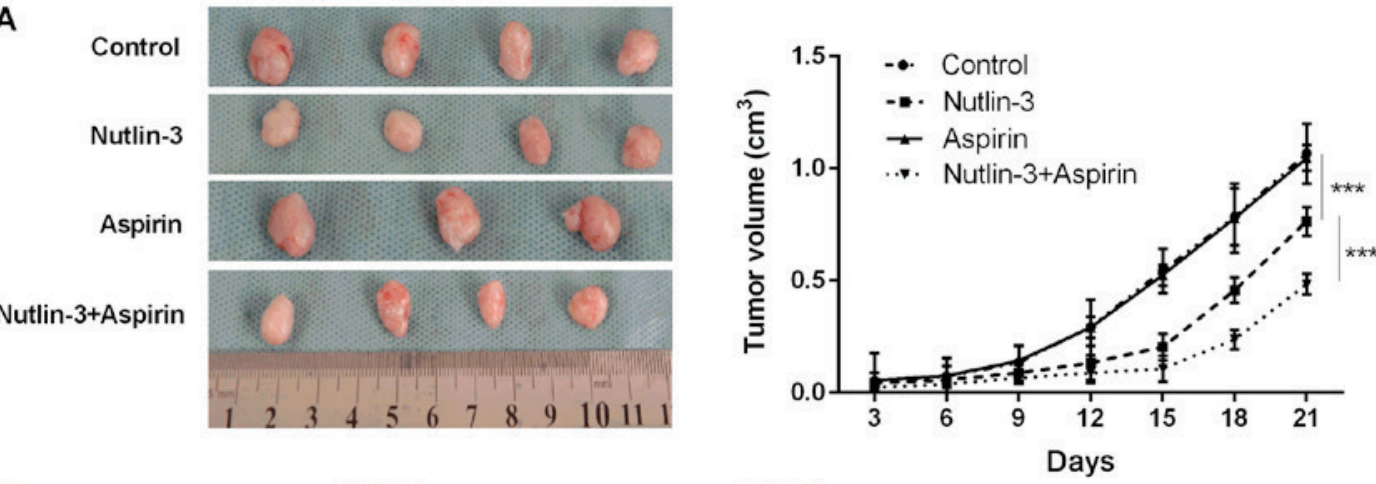

B

Control

Nutlin-3
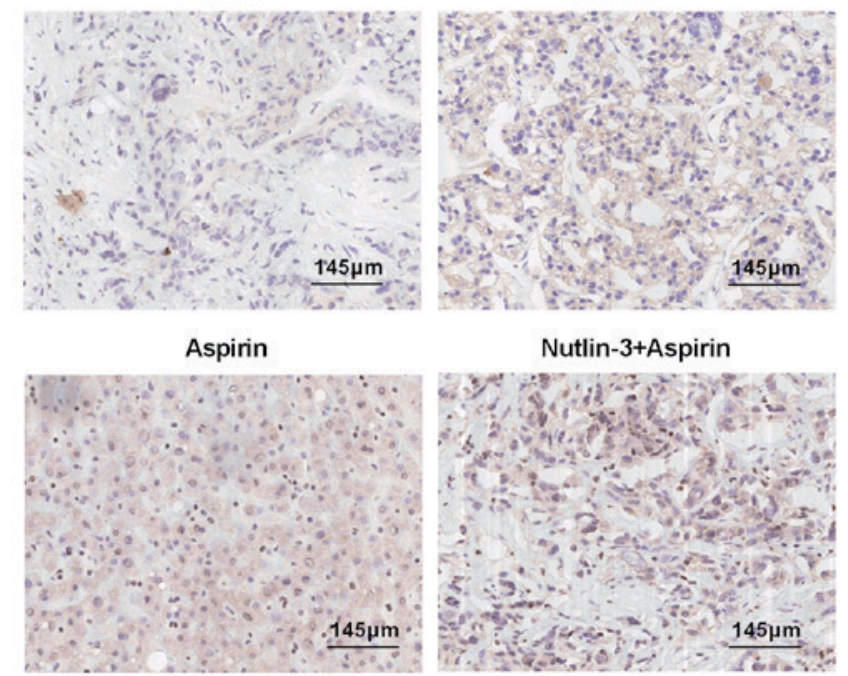

C
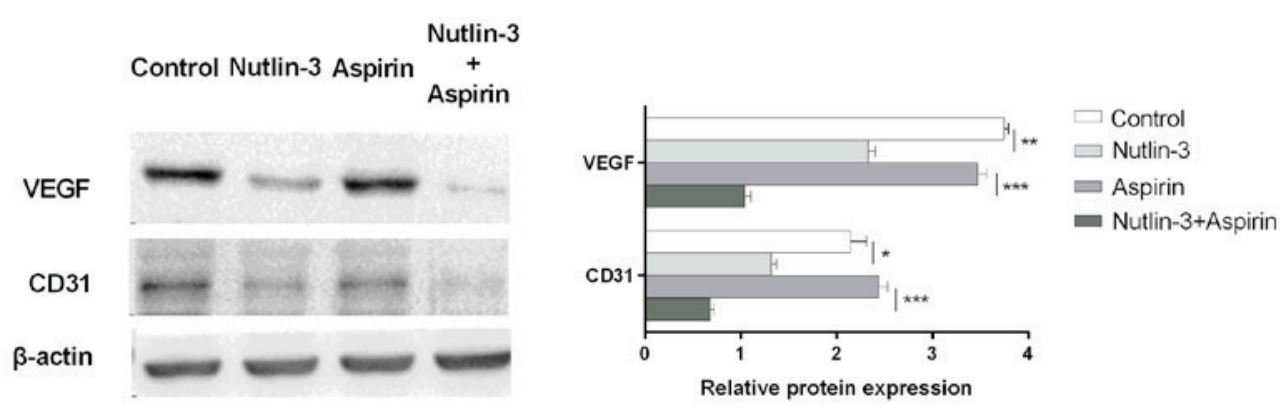

Figure 5. (A) In vivo study, the volume of xenografts derive from HepG2 cells in four groups. The tumor images corresponding to hepatocellular carcinoma (HCC) xenografts tumor in four groups. (B) Bax expression in tumor tissue from xenografted mice in four groups (magnification, x400). (C) VEGF and CD31 expression in tumor tissues of mice transplanted HepG2 cells and administrated with aspirin and/or nutlin-3 were detected using RT-qPCR. Data are means \pm standard deviation (error bars). $\mathrm{P}<0.05 ;{ }^{* *} \mathrm{P}<0.01 ;{ }^{* * *} \mathrm{P}<0.0001$.

also in hepatoblastoma. However, the general applicability in other liver cancer type is still unknown.

Aspirin is a common clinic drugs which was approved to control postoperative pain, inflammation and prevent cardiovascular disease. Recently, a large number of researches and epidemiological studies has demonstrated that the use of nonsteroidal anti-inflammatory drugs (NSAIDs) protects against the incidence and development of certain cancers. In our study, aspirin can inhibit the proliferation and invasion of HepG2 cell line with a dose-manner administration. The animal experiment has also clarified the phenomena in vivo such as the smaller tumor volume in treatment group with aspirin. In actually, Aspirin is the most popular of being investigated in different types of cancers (31-33). It has been used in chemoprevention of many malignant cancers. And effective taking aspirin need to be dose and time dependent. However, patients on high-dose aspirin ( $\geq 500 \mathrm{mg}$ daily) might induce bleeding complications which limit the clinical application value of aspirin.

Drug-drug interactions (DDIs) is a new method to deal with the problem of adverse drug events. The drug positively or negatively impact the clinical effect or plasma concentration of another drug even be a significant cause of morbidity and mortality worldwide. Aspirin inhibit the prevention, progression, and metastatic growth of cancer by the inhibition of COX-2 and platelet aggregation (34-36). The expression of COX-2 is associated with increased cell proliferation and tumor promotion significantly. In addition, aspirin can promote platelet aggregation which could contribute to immune evasion. And platelets could induce abnormal COX-2 levels which can 
decrease the oncosuppressor genes and decrease the oncogenes in colon carcinoma (37). Moreover, some COX-2 independent pathways have been investigated to elucidate aspirin mechanism including $\mathrm{NF}-\kappa \mathrm{B}, \mathrm{ERK}, \mathrm{Bcl}-2 / \mathrm{Bax}$ signaling pathway, TGF- $\beta$ /Smads signaling pathway, JAK1/STAT1 pathway, PI3K/Akt signaling pathway and vascular endothelial growth factor (VEGF) signaling (11,38-41). Due to the mechanism is related with cells angiogenesis, cell proliferation and migration, especially apoptosis, we wondered to uncover a new drug to cooperate with aspirin for inducing tumor cells' apoptosis. P53 is the classical anti-apoptosis gene and a key protein in regulating tumor cells' apoptosis. Previous study showed that inhibition of P53 suppression by MDM2 in cancer cells promotes growth arrest, apoptosis and senescence in vitro and in vivo. Nutlin-3 has been demonstrated that induces cell cycle arrest and apoptosis by downregulates p53 phosphorylation on serine $^{392}$ in HCC cells (27). In consist with previous researches, in this study, a similar growth inhibition and apoptosis effect of nutlin-3 were found in HepG2 cell lines. Moreover, combination between nutlin-3 and aspirin not only reduced the proliferation of HepG 2 cells but also enhanced its apoptosis significantly. The western blot result showed an outstanding upregulation of caspase- 3 and caspase- 9 in co-treatment group of nutlin-3 and aspirin compared with other groups treated with nutlin-3 and aspirin alone. These two proteinase paly essential role for being blocked the recruitment of procadpase- 9 to the Apaf-1/dATP/cytochrome $c$ apoptosome complex (42). As we all know, Bax promotes the release of cytochrome $c$, and activates caspase- 9 and caspase-3. Bcl-2/Bax is directly regulated by the tumor suppressor P53 and has been shown to be involved in P53-mediated apoptosis $(43,44)$. We suggested that the synergistic effect between nutlin-3 and aspirin exert apoptosis function by $\mathrm{Bcl}-2 / \mathrm{Bax}$ signaling pathway. In consist with our assumption, the expression of Bax was raised according different time continually. Therefore, these data demonstrate that in HepG2 cell Bax is associated with the apoptosis.

The applicable concentration of drug is a key issue in clinic. Although aspirin has been a common therapy in clinic for anti-inflammation and improving cardiovascular disease, the value of preventing and controlling tumor is limited by its adverse drug events. To make sure the effective clinical function, the blood medicinal concentration of aspirin is 1-3 mmol/l. And a report proved the safe concentration of aspirin is $30-1,500 \mathrm{mg} /$ day (45). However, approximately $90 \%$ of the liver cancer patients have liver cirrhosis which show liver dysfunction in different levels and portal hypertension. Using of high-dose aspirin would induce gastrointestinal bleeding. But if the dose lass than $100 \mathrm{mg}$ daily, it would occur the risk of bleeding. The application value of low dose aspirin has been evidenced in some cancer $(46,47)$. There is a study indicated the low dose aspirin (300-75 mg daily) also can reduce colorectal cancer incidence and mortality, especially proximal colon cancer by a 20 years follow-up of five randomized trials (47). In our animal model, nude mouse were chosen to build model of transplantable subcutaneously tumors in mouse. Because the nude mice's capability of adapting themselves to the drug administration was weaker than the normal mice. We determined the concentration of aspirin as $15 \mathrm{mg} / \mathrm{kg} / \mathrm{day}$, p.o. according previous reports $(40,48)$. However, mice all died after treating with aspirin in succession. Therefore, we lowered drug concentration (13 mg/kg/day, p.o.) to fit experiment demands. The tumor volume for combination therapy of aspirin and nutlin-3 is decrease compared with other groups and no side effects were observed. It indicated that the combinations of low dose aspirin and nutlin-3 regularly has no risk of bleeding and assure the effective drug concentration in HCC. We can assume that a study is feasible to determine an optimal concentration to improve the efficacy of aspirin in clinic.

In conclusion, our present results indicated that the treatment of aspirin and nutlin-3 alone or in combination both inhibit growth and promote apoptosis in vitro and in vivo. Nutlin-3 enhances the apoptosis effect of a low dose of aspirin by upregulating Bax expression in HepG 2 cell line and in vivo. The synergistic effect of nutlin-3 in aspirin antitumor therapy contribute to diminish the dose of aspirin and decrease the rise of adverse drug events which would expand aspirin therapeutic and/or adjuvant therapeutic application in the treatment of $\mathrm{HCC}$ in clinical.

\section{References}

1. Gish RG: Hepatocellular carcinoma: Overcoming challenges in disease management. Clin Gastroenterol Hepatol 4: 252-261, 2006.

2. Tsoulfas G, Agorastou P, Tooulias A and Marakis GN: Current and future challenges in the surgical treatment of hepatocellular carcinoma: A review. Int Surg 99: 779-786, 2014.

3. Chattopadhyay M, Kodela R, Nath N, Barsegian A, Boring D and Kashfi K: Hydrogen sulfide-releasing aspirin suppresses NF- $\mathrm{KB}$ signaling in estrogen receptor negative breast cancer cells in vitro and in vivo. Biochem Pharmacol 83: 723-732, 2012.

4. Yiannakopoulou ECh: Aspirin and NSAIDs for breast cancer chemoprevention. Eur J Cancer Prev 24: 416-421, 2015.

5. Wang X, Diao Y, Liu Y, Gao N, Gao D, Wan Y, Zhong J and Jin G: Synergistic apoptosis-inducing effect of aspirin and isosorbide mononitrate on human colon cancer cells. Mol Med Rep 12: 4750-4758, 2015.

6. Xiang S, Sun Z, He Q, Yan F, Wang Y and Zhang J: Aspirin inhibits ErbB2 to induce apoptosis in cervical cancer cells. Med Oncol 27: 379-387, 2010.

7. Shen X, Han L, Ma Z, Chen C, Duan W, Yu S, Li P, Zhang L, Li W, Xu Q and Ma Q: Aspirin: A potential therapeutic approach in pancreatic cancer. Curr Med Chem 20: 4153-4162, 2013.

8. Liu JF, Jamieson GG, Wu TC, Zhu GJ and Drew PA: A preliminary study on the postoperative survival of patients given aspirin after resection for squamous cell carcinoma of the esophagus or adenocarcinoma of the cardia. Ann Surg Oncol 16: 1397-1402, 2009.

9. Mc Menamin ÚC, Cardwell CR, Hughes CM and Murray LJ: Low-dose aspirin use and survival in breast cancer patients: A nationwide cohort study. Cancer Epidemiol 47: 20-27, 2017.

10. Frouws MA, Bastiaannet E, Langley RE, Chia WK, van Herk-Sukel MP, Lemmens VE, Putter H, Hartgrink HH, Bonsing BA, Van de Velde CJ, et al: Effect of low-dose aspirin use on survival of patients with gastrointestinal malignancies; an observational study. Br J Cancer 116: 405-413, 2017.

11. Kastrati I, Litosh VA, Zhao S, Alvarez M, Thatcher GR and Frasor J: A novel aspirin prodrug inhibits $\mathrm{NF \kappa B}$ activity and breast cancer stem cell properties. BMC Cancer 15: 845, 2015.

12. Rao CV, Reddy BS, Steele VE, Wang CX, Liu X, Ouyang N, Patlolla JM, Simi B, Kopelovich L and Rigas B: Nitric oxide-releasing aspirin and indomethacin are potent inhibitors against colon cancer in azoxymethane-treated rats: Effects on molecular targets. Mol Cancer Ther 5: 1530-1538, 2006.

13. Bhat IA, Rasool R, Qasim I, Masoodi KZ, Paul SA, Bhat BA, Ganaie FA, Aziz SA and Shah ZA: COX-2 overexpression and $-8473 \mathrm{~T} / \mathrm{C}$ polymorphism in 3'UTR in non-small cell lung cancer. Tumour Biol 35: 11209-11218, 2014.

14. Buskens CJ, Ristimäki A, Offerhaus GJ, Richel DJ and van Lanschot JJ: Role of cyclooxygenase-2 in the development and treatment of oesophageal adenocarcinoma. Scand J Gastroenterol Suppl: 87-93, 2003.

15. Singh Ranger G: The role of aspirin in colorectal cancer chemoprevention. Crit Rev Oncol Hematol 104: 87-90, 2016. 
16. Sciulli MG, Filabozzi P, Tacconelli S, Padovano R, Ricciotti E, Capone ML, Grana M, Carnevale V and Patrignani P: Platelet activation in patients with colorectal cancer. Prostaglandins Leukot Essent Fatty Acids 72: 79-83, 2005.

17. Polanski R, Noon AP, Blaydes J, Phillips A, Rubbi CP, Parsons K, Vlatković N and Boyd MT: Senescence induction in renal carcinoma cells by Nutlin-3: A potential therapeutic strategy based on MDM2 antagonism. Cancer Lett 353: 211-219, 2014.

18. Shangary S and Wang S: Small-molecule inhibitors of the MDM2-p53 protein-protein interaction to reactivate p53 function: A novel approach for cancer therapy. Annu Rev Pharmacol Toxicol 49: 223-241, 2009.

19. Yang P, Chen W, Li X, Eilers G, He Q, Liu L, Wu Y, Wu Y, Yu W, Fletcher JA and Ou WB: Downregulation of cyclin D1 sensitizes cancer cells to MDM2 antagonist Nutlin-3. Oncotarget 7: 32652-32663, 2016.

20. Pechackova S, Burdova K, Benada J, Kleiblova P, Jenikova G and Macurek L: Inhibition of WIP1 phosphatase sensitizes breast cancer cells to genotoxic stress and to MDM2 antagonist nutlin-3. Oncotarget 7: 14458-14475, 2016.

21. Ghassemifar S and Mendrysa SM: MDM2 antagonism by nutlin-3 induces death in human medulloblastoma cells. Neurosc Lett 513: 106-110, 2012

22. Secchiero P, Bosco R, Celeghini C and Zauli G: Recent advances in the therapeutic perspectives of Nutlin-3. Curr Pharm Des 17: 569-577, 2011.

23. Endo S, Yamato K, Hirai S, Moriwaki T, Fukuda K, Suzuki H, Abei M, Nakagawa I and Hyodo I: Potent in vitro and in vivo antitumor effects of MDM2 inhibitor nutlin-3 in gastric cancer cells. Cancer Sci 102: 605-613, 2011.

24. Zanjirband M, Edmondson RJ and Lunec J: Pre-clinical efficacy and synergistic potential of the MDM2-p53 antagonists, Nutlin-3 and RG7388, as single agents and in combined treatment with cisplatin in ovarian cancer. Oncotarget 7: 40115-40134, 2016.

25. Zheng T, Yin D, Lu Z, Wang J, Li Y, Chen X, Liang Y, Song X, Qi S, Sun B, et al: Nutlin-3 overcomes arsenic trioxide resistance and tumor metastasis mediated by mutant p53 in hepatocellular carcinoma. Mol Cancer 13: 133, 2014

26. Shao QS, Ye ZY, Ling ZQ and Ke JJ: Cell cycle arrest and apoptotic cell death in cultured human gastric carcinoma cells mediated by arsenic trioxide. World J Gastroenterol 11: 3451-3456, 2005.

27. Shi X, Liu J, Ren L, Mao N, Tan F, Ding N, Yang J and Li M: Nutlin-3 downregulates p53 phosphorylation on serine392 and induces apoptosis in hepatocellular carcinoma cells. BMB Rep 47: 221-226, 2014.

28. Wang J, Zheng T, Chen X, Song X, Meng X, Bhatta N, Pan S, Jiang $\mathrm{H}$ and Liu L: MDM2 antagonist can inhibit tumor growth in hepatocellular carcinoma with different types of p53 in vitro. J Gastroenterol Hepatol 26: 371-377, 2011.

29. Aden DP, Fogel A, Plotkin S, Damjanov I and Knowles BB Controlled synthesis of HBsAg in a differentiated human liver carcinoma-derived cell line. Nature 282: 615-616, 1979.

30. López-Terrada D, Cheung SW, Finegold MJ and Knowles BB: Hep G2 is a hepatoblastoma-derived cell line. Human Pathol 40 $1512-1515,2009$

31. Tougeron D, Sha D, Manthravadi S and Sinicrope FA: Aspirin and colorectal cancer: Back to the future. Clin Cancer Res 20 1087-1094, 2014

32. Maity G, De A, Das A, Banerjee S, Sarkar S and Banerjee SK: Aspirin blocks growth of breast tumor cells and tumor-initiating cells and induces reprogramming factors of mesenchymal to epithelial transition. Lab Invest 95: 702-717, 2015.

33. Wang Y, Shen C, Ge J and Duan H: Regular aspirin use and stomach cancer risk in China. Eur J Surg Oncol 41: 801-804, 2015 .
34. Lin HY, Delmas D, Vang O, Hsieh TC, Lin S, Cheng GY, Chiang HL, Chen CE, Tang HY, Crawford DR, et al: Mechanisms of ceramide-induced COX-2-dependent apoptosis in human ovarian cancer OVCAR-3 cells partially overlapped with resveratrol. J Cell Biochem 114: 1940-1954, 2013.

35. Xu L, Stevens J, Hilton MB, Seaman S, Conrads TP, Veenstra TD, Logsdon D, Morris H, Swing DA, Patel NL, et al: COX-2 inhibition potentiates antiangiogenic cancer therapy and prevents metastasis in preclinical models. Sci Transl Med 6: 242ra84, 2014.

36. Cronin-Fenton DP, Heide-Jørgensen U, Ahern TP, Lash TL, Christiansen P, Ejlertsen B and Sørensen HT: Low-dose aspirin, nonsteroidal anti-inflammatory drugs, selective COX-2 inhibitors and breast cancer recurrence. Epidemiology 27: 586-593, 2016.

37. Santilli F, Boccatonda A and Davi G: Aspirin, platelets, and cancer: The point of view of the internist. Eur J Intern Med 34: 11-20, 2016

38. Qin HX, Yang J, Cui HK, Li SP, Zhang W, Ding XL and Xia YH: Synergistic antitumor activity of reversine combined with aspirin in cervical carcinoma in vitro and in vivo. Cytotechnology 65: 643-653, 2013

39. Shu Y, Liu Y, Li X, Cao L, Yuan X, Li W and Cao Q: Aspirin-triggered resolvin D1 inhibits TGF- $\beta 1$-induced EndMT through increasing the expression of smad7 and is closely related to oxidative stress. Biomol Ther (Seoul) 24: 132-139, 2016.

40. Li T, Dong ZR, Guo ZY, Wang CH, Tang ZY, Qu SF, Chen ZT, Li XW and Zhi XT: Aspirin enhances IFN- $\alpha$-induced growth inhibition and apoptosis of hepatocellular carcinoma via JAK1/STAT1 pathway. Cancer Gene Ther 20: 366-374, 2013.

41. Ding JH, Yuan LY, Huang RB and Chen GA: Aspirin inhibits proliferation and induces apoptosis of multiple myeloma cells through regulation of $\mathrm{Bcl}-2$ and $\mathrm{Bax}$ and suppression of VEGF. Eur J Haematol 93: 329-339, 2014.

42. Beere HM, Wolf BB, Cain K, Mosser DD, Mahboubi A, Kuwana T, Tailor P, Morimoto RI, Cohen GM and Green DR: Heat-shock protein 70 inhibits apoptosis by preventing recruitment of procaspase-9 to the Apaf-1 apoptosome. Nat Cell Biol 2: 469-475, 2000

43. Lee SY, Choi HC, Choe YJ, Shin SJ, Lee SH and Kim HS Nutlin-3 induces BCL2A1 expression by activating ELK1 through the mitochondrial p53-ROS-ERK1/2 pathway. Int J Oncol 45: 675-682, 2014.

44. Lee SY, Choe YJ, Park JY, Lee SS, Kim YH, Shin SJ, Chung YJ and Kim HS: Wilms' tumor gene 1 enhances nutlin-3-induced apoptosis. Oncol Rep 31: 131-136, 2014.

45. Patrono C, Coller B, Dalen JE, Fuster V, Gent M, Harker LA, Hirsh J and Roth G: Platelet-active drugs: The relationships among dose, effectiveness, and side effects. Chest 114 (5 Suppl): 470S-488S, 1998.

46. Jonsson F, Yin L, Lundholm C, Smedby KE, Czene K and Pawitan Y: Low-dose aspirin use and cancer characteristics: A population-based cohort study. Br J Cancer 109: 1921-1925, 2013.

47. Flossmann E and Rothwell PM; British Doctors Aspirin Trial and the UK-TIA Aspirin Trial: Effect of aspirin on long-term risk of colorectal cancer: Consistent evidence from randomised and observational studies. Lancet 369: 1603-1613, 2007.

48. Lu L, Sun HC, Zhang W, Chai ZT, Zhu XD, Kong LQ, Wang WQ, Zhang KZ, Zhang YY, Zhang QB, et al: Aspirin minimized the pro-metastasis effect of sorafenib and improved survival by up-regulating HTATIP2 in hepatocellular carcinoma. PLoS One 8: e65023, 2013.

This work is licensed under a Creative Commons Attribution-NonCommercial-NoDerivatives 4.0 International (CC BY-NC-ND 4.0) License. 